\title{
Exigência de energia metabolizável de codornas de corte no período de 1 a 14 dias de idade
}

\author{
Carina Scherer ${ }^{1}$, Antonio Claudio Furlan², Elias Nunes Martins², Cláudio Scapinello², \\ Ana Paula Silva Ton ${ }^{1}$
}

\footnotetext{
1 Programa de Pós-Graduação em Zootecnia, Universidade Estadual de Maringá.

2 Departamento de Zootecnia, Universidade Estadual de Maringá.
}

RESUMO - Este experimento foi realizado para estimar a exigência de energia metabolizável (EM) para codornas de corte de 1 a 14 dias de idade. Foram utilizadas 1.140 aves com 1 dia de idade, distribuídas em delineamento inteiramente casualizado, com cinco tratamentos (2.750; 2.850; 2.950; 3.050 e $3.150 \mathrm{kcal}$ de EM/kg de ração), seis repetições e 38 aves por unidade experimental. Observou-se redução linear dos níveis de energia no peso corporal, consumo de ração e ganho de peso das aves. A conversão alimentar foi influenciada de forma quadrática, com melhor estimativa obtida com 2.997 kcal de EM/kg de ração. Enquanto o teor de proteína bruta não sofreu diferença, o teor de água diminuiu e o de extrato etéreo aumentou de forma linear com os níveis crescentes de EM. Os níveis de EM tiveram efeito quadrático sobre a taxa de deposição de proteína e eficiência de deposição de proteína nos cortes. A exigência de EM de codornas de corte na fase inicial de crescimento é de $2.997 \mathrm{kcal}$ de EM/kg, que corresponde à relação energia metabolizável:proteína bruta de 108,9.

Palavras-chave: composição química corporal, Coturnix coturnix sp., deposição de proteína, desempenho

\section{Metabolizable energy requirements of meat quail from 1 to 14 days of age}

\begin{abstract}
This experiment was carried out to estimate the metabolizable energy (ME) requirements for meat quails from 1 to 14 days of age. A total of 1,140 1-day old meat quails were distributed in a completely randomized design, with five treatments $(2,750 ; 2,850 ; 2,950 ; 3,050$ and 3,150 kcal of $\mathrm{ME} / \mathrm{kg})$, six replications and 38 quails per experimental unit. There was linear reduction of energy levels in body weight, feed intake and weight gain of birds. The feed conversion ratio showed a quadratic effect, with the best estimate obtained with 2,997 kcal of $\mathrm{ME} / \mathrm{kg}$. Whereas crude protein content did not differ, water content decreased and ether extract increased linearly with the increasing levels of ME. The ME levels showed a quadratic effect on daily protein accretion rate and daily protein accretion efficiency. The ME requirements for meat quail in the initial growing stage is $2,997 \mathrm{kcal} / \mathrm{kg}$, corresponding to a metabolizable energy/crude protein relation of 108.9.
\end{abstract}

Key Words: body composition, Coturnix coturnix sp., performance, protein accretion

\section{Introdução}

A alimentação representa a maior parte dos custos variáveis de uma atividade avícola, e os teores de proteína bruta e energia metabolizável influem decisivamente no desempenho de codornas, demonstrando extrema importância da estimativa de suas exigências para que se formulem dietas de mínimo custo ou de máximo retorno (Oliveira et al., 2002). Entre as exigências nutricionais, a de energia é muito importante, pois este é o componente nutricional que regula o consumo e, consequentemente, o desempenho das aves e, tanto o excesso quanto à deficiência no consumo de ração, ocasionam perda de produtividade (Barreto et al., 2007b).
O balanceamento das rações para melhorar o desempenho de codornas ainda é um desafio. Por haver poucos trabalhos sobre exigências nutricionais destas aves no Brasil, têm-se utilizado tabelas de exigências nutricionais preconizadas pelo NRC (1994) e INRA (1998), que certamente não são apropriadas às aves criadas nas condições brasileiras (Moura et al., 2008). Além disso, os dados são direcionados às codornas japonesas, o que não é adequado, devido às diferenças fisiológicas em relação à codornas de corte, que apresentam maiores pesos e taxas de crescimento em comparação às de postura (Corrêa et al., 2006).

Corrêa et al. (2007b) avaliaram a exigência de energia metabolizável para codornas de corte e observaram que o máximo desempenho foi alcançado no grupo de aves que 
recebeu ração formulada com $2.900 \mathrm{kcal}$ de EM/kg no período de 7 a 21 dias de idade. Da mesma forma, Rezende et al.(2004) determinaram exigências de $2.900 \mathrm{kcal}$ de EM/kg para codornas francesas na fase inicial, de 1 a 14 dias. De acordo com Freitas et al. (2006), rações para codornas europeias destinadas à produção de carne podem ser formuladas com $2.865 \mathrm{kcal}$ de EM/kg para o período de 1 a 42 dias de idade. Segundo Corrêa et al. (2007a), no entanto, maiores ganhos de peso são estimados com a utilização de 3.100 kcal de EM/kg no período de 7 a 14 dias de idade, não chegando a um valor adequado para estas aves na primeira semana de vida.

Nesse contexto, os estudos envolvendo nutrição e principalmente a determinação das exigências nutricionais dessas aves são de grande importância. O custo de produção tem elevado com o alto preço das fontes proteicas e energéticas da ração. Além disso, normalmente são utilizadas tabelas de exigências nutricionais de outros países, ou de outras espécies de aves, que não são ideais para obtenção do máximo desempenho das codornas de corte, principalmente quando consideradas as condições climáticas brasileiras.

Assim, realizou-se este trabalho com o objetivo de estimar a exigência nutricional de energia metabolizável para codornas de corte na fase inicial de crescimento, de 1 a 14 dias de idade.

\section{Material e Métodos}

O experimento foi realizado no Setor de Coturnicultura da Fazenda Experimental de Iguatemi da Universidade Estadual de Maringá. Foram alojadas 1.140 codornas de corte com 1 dia de idade, não sexadas, distribuídas de forma uniforme em galpão convencional dividido em boxes de $2,5 \mathrm{~m}^{2}$, com cobertura de telha de fibra amianto, piso de terra batida e paredes laterais de alvenaria com telas de arame até o telhado, providas de cortinas laterais. Foi utilizada cama de palha de arroz sobre o piso.

Em cada unidade experimental (boxe), foram utilizados círculos de proteção e campânula como fonte de aquecimento para os pintinhos. A cama foi forrada com papelão até o sétimo dia de idade.

O delineamento experimental foi inteiramente casualizado, com cinco tratamentos, seis repetições e 38 aves por unidade experimental. Os tratamentos consistiram de cinco níveis de energia metabolizável (EM) (2.750; 2.850; 2.950; 3.050 e $3.150 \mathrm{kcal}$ de EM/kg de ração) em rações formuladas à base de milho, farelo de soja e glúten de milho (Tabela 1), conforme valores de composição química e energética apresentados por Rostagno et al. (2005).

Os teores de metionina+cistina, treonina e triptofano digestíveis das rações foram calculados de acordo com a

Tabela 1 - Composição centesimal e química das rações experimentais para codornas de corte na fase de 1 a 14 dias de idade

\begin{tabular}{|c|c|c|c|c|c|}
\hline Ingrediente (kg) & \multicolumn{5}{|c|}{ Nível de energia metabolizável (kcal/kg de ração) } \\
\hline Milho grão & 44,080 & 43,320 & 42,540 & 41,770 & 41,000 \\
\hline Glúten de milho (60\%) & - & 1,787 & 3,563 & 5,342 & 7,118 \\
\hline Óleo de soja & 0,740 & 2,000 & 3,270 & 4,535 & 5,800 \\
\hline Fosfato bicálcico & 1,518 & 1,529 & 1,541 & 1,553 & 1,564 \\
\hline DL-metionina & 0,295 & 0,283 & 0,271 & 0,258 & 0,246 \\
\hline L-treonina & - & - & - & 0,002 & 0,007 \\
\hline Sal comum & 0,400 & 0,400 & 0,400 & 0,400 & 0,400 \\
\hline Suplemento vitamínico/mineral ${ }^{1}$ & 0,300 & 0,300 & 0,300 & 0,300 & 0,300 \\
\hline Antioxidante $^{2}$ & 0,010 & 0,010 & 0,010 & 0,010 & 0,010 \\
\hline Total & 100,00 & 100,00 & 100,00 & 100,00 & 100,00 \\
\hline Treonina digestível (\%) & 0,93 & 0,93 & 0,93 & 0,93 & 0,93 \\
\hline Triptofano digestível (\%) & 0,23 & 0,23 & 0,23 & 0,23 & 0,23 \\
\hline Cálcio (\%) & 0,65 & 0,65 & 0,65 & 0,65 & 0,65 \\
\hline Fósforo disponível (\%) & 0,41 & 0,41 & 0,41 & 0,41 & 0,41 \\
\hline Extrato etéreo (\%) & 3,19 & 4,42 & 5,66 & 6,89 & 8,11 \\
\hline Sódio (\%) & 0,18 & 0,18 & 0,18 & 0,18 & 0,18 \\
\hline
\end{tabular}


relação de proteína ideal proposta por Rostagno et al. (2005) para frangos de corte na fase inicial considerando o teor de lisina digestível utilizado obtido por Ton (2007). O teor de proteína bruta foi calculado a partir de dados de Otutumi et al. (2009) e os teores de cálcio e fósforo disponível foram obtidos em dados publicados por Silva et al. (2009).

Aos 14 dias de idade, as aves e as sobras de ração foram pesadas para cálculo dos parâmetros de desempenho: peso final (g), ganho de peso (g), consumo de ração (g) e conversão alimentar (g/g). Foi avaliada a composição química corporal, utilizando peito e pernas (coxa e sobrecoxa) com pele, de cinco aves selecionadas pelo peso médio ( $\pm 10 \%)$ de cada unidade experimental, sacrificadas por decapitação entre os ossos occipital e atlas, depenadas e evisceradas manualmente.

Os cortes foram acondicionados em sacos plásticos, congelados, e posteriormente moídos e homogeneizados, levados a estufa de ventilação forçada a $55^{\circ} \mathrm{C}$ por 72 horas para pré-secagem. Depois, foram processados em moinho tipo bola e conduzidos ao laboratório de nutrição animal para as análises de matéria seca, proteína bruta e extrato etéreo, conforme metodologia descrita por Silva \& Queiroz (2004).

Para determinação da taxa de deposição de proteína e gordura nos cortes (g/dia), foi utilizada a metodologia adaptada de Fraga et al. (2008). A taxa de deposição de proteína (TDP) foi mensurada comparando as codornas abatidas ao término do período experimental em relação a um grupo adicional de 20 codornas abatidas ao nascimento, utilizando a seguinte fórmula:

$\mathrm{TDP}=\left(\mathrm{QP}_{\mathrm{cf}}-\mathrm{QP}_{\mathrm{ci}}\right) / \mathrm{PE}$,

em que: $\mathrm{QP}_{\mathrm{cf}}=$ quantidade, em gramas, de proteína nos cortes finais; $\mathrm{QP}_{\mathrm{ci}}=$ quantidade de proteína, em gramas, nos cortes iniciais; e PE = período experimental, em dias. A $\mathrm{QP}_{\mathrm{cf}}$ foi obtida multiplicando-se o peso médio dos cortes das aves de cada unidade experimental, ao final do experimento, pelo respectivo teor de proteína bruta dos cortes, enquanto $\mathrm{QP}_{\mathrm{ci}}$ foi obtida pelo peso médio dos cortes do grupo de 20 codornas abatidas inicialmente, multiplicado pelo seu teor médio de proteína bruta.

A taxa de deposição de gordura (TDG) foi calculada segundo a equação:

$\mathrm{TDG}=\left(\mathrm{QG}_{\mathrm{cf}}-\mathrm{QG}_{\mathrm{Ci}}\right) / \mathrm{PE}$,

em que: $\mathrm{QG}_{\mathrm{cf}}=$ quantidade, em gramas, de gordura nos cortes finais; $\mathrm{QG}_{\mathrm{ci}}=$ quantidade de gordura nos cortes iniciais; $\mathrm{e}$ $\mathrm{PE}$ = período experimental, em dias. $\mathrm{QG}_{\mathrm{cf}} \mathrm{eQP}$. foram obtidas de modo similar as $\mathrm{QP}_{\mathrm{cf}}$ e $\mathrm{QP}_{\mathrm{ci}}$, utilizando-se os valores de extrato etéreo dos cortes em vez de proteína bruta.

Para calcular a eficiência de deposição de proteína (g) e a energia (kcal/dia) retida nos cortes, foi utilizada a metodologia adaptada de Fraga (2002). A eficiência de deposição de proteína (EDP) foi calculada pela fórmula: $\mathrm{EDP}=\mathrm{TDP} / \mathrm{CDL}$, em que: TDP = taxa de deposição de proteína, em gramas; e CDL = consumo diário de lisina, em gramas.

A análise estatística dos dados foi realizada por meio do programa Sistema para Análises Estatísticas -SAEG (1997), da Universidade Federal de Viçosa, e a estimativa de exigência de energia metabolizável obtida por meio de modelo quadrático.

\section{Resultados e Discussão}

A média das temperaturas mínima e máxima registradas durante o período experimental foi 26 e $35^{\circ} \mathrm{C}$, respectivamente. Houve efeito linear dos níveis de EM sobre o consumo de ração (CR) (Tabela 2), que reduziu $(\mathrm{P}<0,05)$ conforme aumentou o nível energético da ração. Resultados similares foram descritos por Corrêa et al. (2007a), Corrêa et al. (2007b), Freitas et al. (2006), Freitas et al. (2005), Rezende et al. (2004) e Pinto et al. (2002), que observaram redução significativa do consumo de ração com o aumento dos níveis de energia das rações.

Tabela 2 - Peso corporal (PC), consumo de ração (CR), ganho de peso (GP) e conversão alimentar (CA) das codornas de corte aos 14 dias de idade

\begin{tabular}{|c|c|c|c|c|c|c|c|}
\hline \multirow[t]{2}{*}{ Parâmetro } & \multicolumn{5}{|c|}{ Nível de energia metabolizável (kcal/kg) } & \multirow[t]{2}{*}{$\mathrm{CV}$} & \multirow[t]{2}{*}{ Efeito $^{1}$} \\
\hline & 2.750 & 2.850 & 2.950 & 3.050 & 3.150 & & \\
\hline Consumo de ração (g) & 129,60 & 126,29 & 114,06 & 109,33 & 103,69 & 3,23 & $\operatorname{Lin}^{2}$ \\
\hline Peso corporal (g) & 72,10 & 71,82 & 69,53 & 64,86 & 61,59 & 4,53 & $\operatorname{Lin}^{2}$ \\
\hline Ganho de peso (g) & 62,96 & 62,66 & 60,44 & 55,82 & 52,45 & 5,16 & $\operatorname{Lin}^{2}$ \\
\hline Conversão alimentar (g/g) & 2,06 & 2,02 & 1,89 & 1,96 & 1,98 & 4,74 & Qua $^{3}$ \\
\hline \multicolumn{6}{|l|}{ Equações de regressão } & \multicolumn{2}{|c|}{$\mathrm{R}^{2}$} \\
\hline \multirow{2}{*}{\multicolumn{6}{|c|}{$\begin{array}{l}\mathrm{CR}=319,516-0,0687876 \mathrm{EM} \\
\mathrm{PC}=150,484-0,0279679 \mathrm{EM}\end{array}$}} & \multicolumn{2}{|c|}{0,86} \\
\hline & & & & & & \multicolumn{2}{|c|}{0,62} \\
\hline \multicolumn{6}{|l|}{$\mathrm{GP}=141,032-0,0278538 \mathrm{EM}$} & & \\
\hline \multicolumn{6}{|c|}{$\mathrm{CA}=22,6859-0,0138503 \mathrm{EM}+0,00000231068 \mathrm{EM}^{2}$} & \multicolumn{2}{|c|}{$\begin{array}{l}0,62 \\
0,75\end{array}$} \\
\hline
\end{tabular}

EM = energia metabolizável; CV = coeficiente de variação.

${ }^{1}$ Análise de regressão; ${ }^{2}$ Efeito linear da EM; ${ }^{3}$ Efeito quadrático da EM. 
De acordo com Corrêa et al. (2007a), as codornas que consomem ração com menor teor energético tendem a compensar a insuficiente ingestão de energia, aumentando o consumo para atender às exigências de energia para suas funções fisiológicas. Por sua vez, níveis elevados de energia na ração induzem a menor ingestão para evitar o excesso de energia no organismo. Dessa forma, as codornas de corte, assim como os frangos de corte, tendem a regular seu consumo de acordo com o nível energético da ração, um dos fatores mais importantes na regulação do consumo pelas aves (Barreto et al., 2007).

O peso corporal (PC) das aves, aos 14 dias de idade, reduziu linearmente $(\mathrm{P}<0,05)$ com o aumento dos níveis de EM das rações (Tabela 2), mesmo efeito observado $(\mathrm{P}<0,05)$ no ganho de peso (GP) das aves. Esse resultado pode ser atribuído à redução no consumo de ração à medida que aumentou o nível de energia da ração. Assim, a tentativa das codornas alimentadas com as rações mais energéticas em manter o nível da ingestão de energia resultou em menor ingestão dos demais nutrientes da ração, uma vez que estes foram mantidos constantes.

De acordo com Silva \& Ribeiro (2001), na fase de 1 a 14 dias de idade, o ganho de peso das codornas pode chegar até sete vezes o valor do peso inicial. Segundo os autores, isso é ocasionado pela hipertrofia celular, principalmente dos músculos peitorais, do crescimento dos ossos e das vísceras, fato que comprova a importância do consumo de ração formulada com níveis adequados de aminoácidos, principalmente a lisina, que é fundamental para a deposição de proteína muscular, além do cálcio e do fósforo, necessários para a formação do tecido ósseo durante a fase inicial de crescimento. Dessa forma, a ingestão desses nutrientes em quantidade abaixo das exigências pode comprometer o crescimento das aves conforme observado nesta pesquisa.

Houve efeito quadrático $(\mathrm{P}<0,05)$ dos níveis de $\mathrm{EM}$ sobre a conversão alimentar (CA), e isso indica que a melhor estimativa (1,93 g/g) foi obtida com rações contendo $2.997 \mathrm{kcal}$ de EM/kg. Este valor de EM confirma os resultados obtidos por Rezende et al. (2004), que obtiveram melhor conversão alimentar com rações contendo $3.000 \mathrm{kcal}$ de EM/kg de ração.

Determinando as exigências quantitativas de energia e proteína para mantença e ganho, Silva et al. (2004) observaram que, quanto maior o ganho desejado, maiores quantidades de ração, proteína e energia devem ser fornecidas às aves. Todavia, essas quantidades devem estar relacionadas à conversão alimentar, pois nem sempre o maior consumo será compensado pela quantidade de peso ganho por estas aves, existindo sempre um nível ótimo entre consumo de ração e ganho de peso que permite o maior retorno econômico.

O teor de matéria seca (MS) dos cortes aumentou linearmente $(\mathrm{P}<0,05)$, enquanto o teor de água diminuiu $(\mathrm{P}<0,05)$, à medida que o nível de $\mathrm{EM}$ das rações aumentou (Tabela 3). Esses resultados podem ser atribuídos ao aumento da quantidade de gordura na carcaça e diferem dos obtidos por Ton et al. (2011), que não observou efeito dos niveis de energia sobre o teor de água de carcaça de codornas de corte aos 35 dias de idade.

O teor de proteína bruta (PB) nos cortes não foi influenciado $(\mathrm{P}>0,05)$ pelos níveis energéticos estudados e isso indica que a menor ingestão de proteína e aminoácidos, decorrentes da redução no consumo de ração pelas aves, pode reduzir o seu tamanho, mas não o teor de $\mathrm{PB}$ nos seus cortes.

Tabela 3 - Composição química dos cortes, taxa de deposição de proteína (TDP), taxa de deposição de gordura (TDG) e eficiência de deposição de proteína (EDP) das codornas de corte aos 14 dias de idade

\begin{tabular}{|c|c|c|c|c|c|c|c|}
\hline \multirow[t]{2}{*}{ Parâmetro } & \multicolumn{5}{|c|}{ Nível de energia metabolizável (kcal/kg) } & \multirow[t]{2}{*}{$\mathrm{CV}$} & \multirow[t]{2}{*}{ Efeito $^{1}$} \\
\hline & 2.750 & 2.850 & 2.950 & 3.050 & 3.150 & & \\
\hline Matéria seca (\%) & 25,85 & 25,47 & 26,80 & 27,38 & 27,49 & 2,43 & $\operatorname{Lin}^{2}$ \\
\hline Água (\%) & 74,15 & 74,53 & 73,20 & 76,62 & 72,51 & 0,88 & $\operatorname{Lin}^{2}$ \\
\hline Proteína bruta (\%) & 18,37 & 18,25 & 18,53 & 19,20 & 18,34 & 2,82 & $\mathrm{NS}^{3}$ \\
\hline Extrato etéreo (\%) & 3,05 & 2,95 & 3,49 & 3,79 & 4,09 & 9,18 & $\operatorname{Lin}^{2}$ \\
\hline TDP (g/dia) & 0,267 & 0,273 & 0,256 & 0,247 & 0,209 & 3,06 & Qua $^{4}$ \\
\hline TDG (g/dia) & 0,042 & 0,042 & 0,046 & 0,049 & 0,045 & 9,45 & $\mathrm{NS}^{3}$ \\
\hline $\operatorname{EDP}(g /$ dia $)$ & 2,05 & 2,14 & 2,19 & 2,27 & 1,97 & 4,60 & Qua $^{4}$ \\
\hline \multicolumn{6}{|l|}{ Equações de regressão } & \multicolumn{2}{|c|}{$\mathrm{R}^{2}$} \\
\hline \multicolumn{6}{|l|}{ Matéria seca $=11,2513+0,00520230$ EM } & \multicolumn{2}{|c|}{0,82} \\
\hline \multicolumn{6}{|l|}{ Água $=88,7487-0,00520229$ EM } & \multicolumn{2}{|c|}{0,82} \\
\hline \multicolumn{6}{|c|}{ Extrato etéreo $=-4,90055+0,00284419$ EM } & \multicolumn{2}{|c|}{0,93} \\
\hline \multicolumn{6}{|c|}{$\mathrm{TDP}=-4,29501+0,00323009 \mathrm{EM}-0,000000571311 \mathrm{EM}^{2}$} & \multicolumn{2}{|c|}{0,97} \\
\hline \multicolumn{6}{|c|}{$\underline{E D P}=-45,1372+0,0321478 E M-0,00000545438 E^{2}$} & \multicolumn{2}{|c|}{0,73} \\
\hline
\end{tabular}

$\mathrm{EM}$ = energia metabolizável; $\mathrm{CV}$ = coeficiente de variação.

${ }^{1}$ Análise de regressão; ${ }^{2}$ Efeito linear da EM; ${ }^{3}$ Não-significativo, ${ }^{4}$ Efeito quadrático da EM. 
O teor de extrato etéreo (EE) dos cortes aumentou de forma linear $(\mathrm{P}<0,05)$ com o aumento dos níveis de EM nas rações. Este efeito pode ser atribuído ao incremento gradativo na inclusão de óleo vegetal, aumentando o teor de extrato etéreo das rações, que refletiu diretamente na deposição de gordura na carcaça, o que também foi observado por Sakomura et al. (2004), que relataram que rações formuladas com altas quantidades de óleo promoveram maior deposição de gordura na carcaça de frangos de corte.

De acordo com Latour et al. (1994), o efeito da suplementação de lipídeos na dieta de aves depende do conteúdo de proteína e dietas com adição de gorduras são bem aproveitadas quando os níveis de proteína são elevados.

Mudanças na propoção de gordura da carcaça também foram verificadas por Rajini \& Narahari (1998), que, em estudo com níveis de proteína e energia na ração de codornas japonesas, verificaram que o maior nível energético resultou em maior teor de gordura na carcaça. De acordo com Bertechini (2006), o aumento dos níveis de energia metabolizável na ração de frangos de corte reduz o consumo alimentar e melhora a conversão alimentar, porém aumenta a deposição de gordura na carcaça, efeito prejudicial à qualidade da carcaça desses animais.

Os níveis de EM influenciaram de forma quadrática $(\mathrm{P}<0,05)$ a taxa de deposição de proteína (TDP) nos cortes aos 14 dias de idade, enquanto a taxa de deposição de gordura (TDG) não sofreu efeito significativo $(\mathrm{P}>0,05)$. A melhor estimativa para a taxa de deposição proteica foi de 0,271 g/dia e foi obtida para o nível de $2.827 \mathrm{kcal}$ de EM $/ \mathrm{kg}$ de ração. Diferentemente, Ton et al. (2011) avaliaram rações contendo níveis crescentes de energia metabolizável e não notaram efeito significativo na taxa de deposição de proteína, porém notaram aumento linear na taxa de deposição de gordura na carcaça de codornas de corte aos 35 dias de idade conforme aumentou o nível energético das rações.

Houve efeito quadrático dos níveis de EM sobre a eficiência de deposição de proteína (EDP) nos cortes das codornas de corte aos 14 dias de idade. A melhor estimativa (2,32 g/dia) de EDP foi obtida para o nível de $2.947 \mathrm{kcal} / \mathrm{kg}$ de ração. De acordo com Ton et al. (2011), os níveis de EM das rações não influenciaram a eficiência de deposição de proteína na carcaça de codornas aos 35 dias de idade.

\section{Conclusões}

A exigência de EM para codornas de corte de 1 a 14 dias de idade é de $2.997 \mathrm{kcal}$ de EM/kg de ração, que corresponde à relação energia metabolizável:proteína bruta de 108,9.

\section{Referências}

BARRETO, S.L.T.; QUIRINO, B.J.S.; BRITO, C.O. et al. Níveis de energia metabolizável para codornas japonesas na fase inicial de postura. Revista Brasileira de Zootecnia, v.36, n.1, p.79-85, 2007a.

BARRETO, S.L.T.; QUIRINO, B.J.S.; BRITO, C.O. et al. Efeitos de níveis nutricionais de energia sobre o desempenho e a qualidade de ovos de codornas européias na fase inicial de postura. Revista Brasileira de Zootecnia, v.36, n.1, p.86-93, 2007b.

BERTECHINI, A.G. Nutrição de monogástricos. Lavras: Editora UFLA, 2006. 301p.

CORRÊA, G.S.S.; SILVA, M.A.; CORRÊA, A.B. et al. Exigência de metionina + cistina total para codornas de corte em crescimento. Arquivo Brasileiro de Medicina Veterinária e Zootecnia, v.58, p.414-420, 2006

CORREAA, G.S.S.; SILVA, M.A.; CORRÊA, A.B. et al. Exigências de proteína bruta e energia metabolizável em codornas de corte durante a fase de crescimento. Arquivo Brasileiro de Medicina Veterinária e Zootecnia, v.59, n.2, p.488-494, 2007a.

CORRÊA, G.S.S.; SILVA, M.A.; CORRÊA, A.B. et al. Exigência de proteína bruta e energia metabolizável para codornas de corte EV1. Arquivo Brasileiro de Medicina Veterinária e Zootecnia, v.59, n.3, p.797-804, 2007b.

FRAGA, A.L.; MOREIRA, I.; FURLAN, A.C. et al. Lysine requirement of starting barrows from two genetic groups fed on low crude protein diets. Brazilian Archives of Biology and Technology, v.51, n.1, p.49-56, 2008.

FRAGA, A.L. Exigência de lisina para suínos em fase inicial $(15-30 \mathrm{~kg})$, de dois grupos genéticos, em rações formuladas de acordo com o conceito de proteína ideal.. 46f. Dissertação (Mestrado em Zootecnia) - Universidade Estadual de Maringá, Maringá.

FREITAS, A.C.; FUENTES, M.F.F.; FREITAS, E.R. et al. Efeito de níveis de proteína bruta e de energia metabolizável na dieta sobre o desempenho de codornas de postura. Revista Brasileira de Zootecnia, v.34, n.3, p.838-846, 2005.

FREITAS, A.C.; FUENTES, M.F.F.; FREITAS, E.R. et al. Níveis de proteína bruta e energia metabolizável na ração para codornas de corte. Revista Brasileira de Zootecnia, v.35, n.4, p.1705-1710, 2006 (supl.).

INSTITUTO NACIONAL DE LA RECHERCHÉ AGRONOMIQUE - INRA Alimentação dos animais monogástricos: suínos, coelhos e aves. 2.ed. São Paulo: Roca, 1999. 245p.

LATOUR, M.A.; PEEBLES, E.D.; BOYLE, C.R. et al. The effects of dietary on growth performance, carcass composition, and feed efficiency in the broiler chick. Poultry Science, v.73, p.1362-1369, 1994.

MOURA, G.S.; BARRETO, S.L.T.; DONZELE, J.L. et al. Dietas de diferentes densidades energéticas mantendo constante a relação energia metabolizável:nutrientes para codornas japonesas em postura. Revista Brasileira de Zootecnia, v.37, n.9, p.1628-1633, 2008.

NATIONAL RESEARCH COUNCIL - NRC. Nutrient requirements of poultry. 9.ed. Washington, D.C.: National Academy of Sciences, 1994. 155p.

OLIVEIRA, N.T.E.; SILVA, M.A.; SOARES, R.T.N. et al. Exigências de proteína bruta e energia metabolizável para codornas japonesas machos criadas para a produção de carne. Arquivo Brasileiro de Medicina Veterinária e Zootecnia, v.54, p.196-203, 2002.

OTUTUMI, L.K.; FURLAN, A.C.; MARTINS, E.N. Efeito do probiótico sobre o desempenho, rendimento de carcaça e exigências nutricionais de proteína bruta de codornas de corte. Revista Brasileira de Zootecnia, v.38, n.2, p.299-306, 2009.

PINTO, R.; FERREIRA, A.S.; ALBINO, L.F.T. et al. Níveis de proteína e energia para codornas japonesas em postura. Revista Brasileira de Zootecnia, v.31, n.4, p.1761-1770, 2002. 
RAJINI, R.A.; NARAHARI, D. Dietary energy and protein requirements of growing japanese quails in the tropics. Indian Journal Animal Science, v.68, p.1082-1086, 1998.

REZENDE, M.J.M.; FLAUZINA, L.P.; McMANUS, C. et al. Desempenho produtivo e biometria das vísceras de codornas francesas alimentadas com diferentes níveis de energia metabolizável e proteína bruta. Acta Scientiarum. Animal Sciences, v.26, n.3, p.353-358, 2004.

ROSTAGNO, H.S.; ALBINO, L.F.T.; DONZELE, J.L. et al. Tabelas brasileiras para aves e suínos: composição de alimentos e exigências nutricionais. 2.ed. Viçosa, MG: UFV, Departamento de Zootecnia, 2005. 186p.

SAKOMURA, N.K.; LONGO, F.A.; RABELLO, C.B. et al. Efeito do nível de energia metabolizável da dieta no desempenho e metabolismo energético de frangos de corte. Revista Brasileira de Zootecnia, v.33, n.6, p.1758-1767, 2004 (supl. 1).

SILVA, D.J.; QUEIROZ, A.C.D. Análises de alimentos: métodos químicos e biológicos. 3.ed. Viçosa, MG: UFV, 2004. $235 p$.

SILVA, K.F.; RIBEIRO, L.G.R. Tabela nacional de exigência nutricional de codornas japonesas (Coturnix coturnix japonica). Bananeiras: DAP/UFPB/Campus IV, 2001. 19p.

SILVA, J.H.V.; SILVA, M.B.; JORDÃO FILHO, J. et al. Exigências de mantença e de ganho de proteína e de energia em codornas japonesas (Coturnix coturnix japonica) na fase de 1 a 12 dias de idade. Revista Brasileira de Zootecnia, v.33, n.5, p.1209-1219, 2004.

SILVA, M.A.; CORRÊA, G.S.S.; CORRÊA, A.B. et al. Influência da proteína bruta e energia metabolizável da dieta sobre a composição de carcaça de codornas européias. In: REUNIÃO ANUAL DA SOCIEDADE BRASILEIRA DE ZOOTECNIA, 42. 2005, Goiânia. Anais... Goiânia: Sociedade Brasileira de Zootecnia/Gmosis, [2005]. (CD-ROM)

SILVA, R.M.; FURLAN, A.C.; TON, A.P.S. et al. Exigências nutricionais de cálcio e fósforo de codornas de corte em crescimento. Revista Brasileira de Zootecnia, v.38, n.8, p.1509-1517, 2009.

TON, A.P.S. Exigências de lisina digestível e energia metabolizável de codornas de corte (Coturnix coturnix sp) em crescimento, com base no conceito de proteína ideal. 2007. 41f. Dissertação (Mestrado em Zootecnia) - Universidade Estadual de Maringá, Maringá.

TON, A.P.S; FURLAN, A.C.; MARTINS, E.N. et al. Exigências de lisina digestível e de energia metabolizável para codornas de corte em crescimento. Revista Brasileira de Zootecnia, v.40, n.3, p.593-601, 2011.

UNIVERSIDADE FEDERAL DE VIÇOSA - UFV. SAEG - Sistema de análises estatísticas e genéticas. Versão 5.0. Viçosa, MG: 1997. 150p. (Manual do usuário). 